\title{
Dynamics and frequency of Gag transmitted polymorphisms in Zambia
}

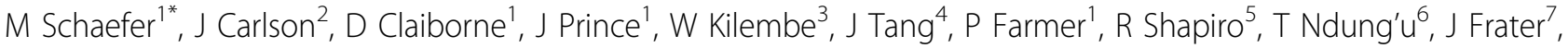 \\ P Goulder ${ }^{7}$, R Kaslow ${ }^{8}$, S Allen ${ }^{1}$, P Goepfert ${ }^{8}$, D Heckerman², E Hunter ${ }^{1}$
}

From AIDS Vaccine 2012

Boston, MA, USA. 9-12 September 2012

\section{Background}

HIV immune escape is not random and follows a predictable mutational path in response to the HLA alleles carried by an individual.

\section{Methods}

Using 143 epidemiologically linked transmission pairs from a Zambian cohort we assessed: (1) the frequency of Gag polymorphisms circulating in the population, (2) if the polymorphisms could be associated with the infected individual's HLA alleles, (3) the frequency at which polymorphisms are transmitted, and (4) the relevance of the transmitted polymorphisms (TP) to the newly infected individual's HLA-I alleles.

\section{Results}

We observed a median of 35 (range 23-66) polymorphisms per chronically infected individual in Gag and $42 \%$ of these polymorphisms could be associated with the individual's HLA (16\% statistically linked, 26\% epitope analysis). When transmission of these polymorphisms was assessed, we observed that the majority of these polymorphisms (84\%) are transmitted to the epidemiologically linked partner and, of these TP, an equivalent fraction $(43 \%$; $11 \%$ statistically linked, $32 \%$ epitope analysis) were relevant to the newly infected individual's HLA-I alleles. In 81 transmission pairs observed during the first two years of infection, we observed a very low overall reversion rate (4\%/year) of the TP. Reversion was not uniform and when p17, p24, p2, p7, p1, and p6 are examined individually, TP in p17 and $\mathrm{p} 2$ exhibited the highest frequency (2.5x) of reversion events based on amino acid length. Four CTL-targeted positions were identified where a majority of TP reverted

${ }^{1}$ Emory University, Atlanta, GA, USA

Full list of author information is available at the end of the article to consensus over the two years of follow up, consistent with a reduction in fitness following transmission.

\section{Conclusion}

These data indicate: (1) HLA-I associated polymorphisms are stable and circulating frequently in the Zambian population, (2) individuals are acquiring HIV-I variants with a high frequency of polymorphisms relevant to their HLA-I alleles, and (3) reversion is slow and not evenly distributed across Gag.

\section{Author details}

${ }^{1}$ Emory University, Atlanta, GA, USA. ${ }^{2}$ Microsoft Research, Redmond, USA. ${ }^{3}$ Zambia Emory HIV Research Project, Lusaka, Zambia. ${ }^{4}$ University of Alabama-Birmingham, Birmingham, USA. ${ }^{5} \mathrm{Harvard}$ School of Public Health, Boston, USA. 'University of KwaZulu-Natal, Durban, South Africa. ${ }^{7}$ Oxford University, UK. ${ }^{8}$ Unviersity of Alabama-Birmingham, USA.

Published: 13 September 2012

\section{doi:10.1186/1742-4690-9-S2-P156}

Cite this article as: Schaefer et al.: Dynamics and frequency of Gag transmitted polymorphisms in Zambia. Retrovirology 2012 9(Suppl 2): P156.

Submit your next manuscript to BioMed Central and take full advantage of:

- Convenient online submission

- Thorough peer review

- No space constraints or color figure charges

- Immediate publication on acceptance

- Inclusion in PubMed, CAS, Scopus and Google Scholar

- Research which is freely available for redistribution

\section{Ciomed Central}

( 2012 Schaefer et al; licensee BioMed Central Ltd. This is an Open Access article distributed under the terms of the Creative Commons Attribution License (http://creativecommons.org/licenses/by/2.0), which permits unrestricted use, distribution, and reproduction in any medium, provided the original work is properly cited. 